J. Dairy Sci. 95:4045-4049

http://dx.doi.org/10.3168/jds.2011-5256

(C) American Dairy Science Association ${ }^{\circledR}, 2012$.

\title{
Short communication: Linear discriminant analysis and type of oil added to dairy goat diets
}

\author{
A. L. Martínez Marín, ${ }^{*}$ P. Gómez-Cortés, $\dagger^{1}$ A. G. Gómez Castro, ${ }^{\star}$ M. Juárez, $†$ L. Pérez Alba, ${ }^{\star}$ \\ M. Pérez Hernández, ${ }^{\star}$ and $M$. A. de la Fuente ${ }^{2}$ \\ *Departamento de Producción Animal (Universidad de Córdoba), Ctra. Madrid-Cádiz, km 396, Campus de Rabanales, 14014 Córdoba, Spain \\ †Instituto de Investigación en Ciencias de la Alimentación (CSIC-UAM), Nicolás Cabrera 9, Universidad Autónoma de Madrid, \\ 28049 Madrid, Spain
}

\section{ABSTRACT}

Gas chromatography fatty acid (FA) analysis of 112 milk fat samples from dairy goats fed a basal diet with no added oil or the same diet with 1 of 3 vegetable oils added [high oleic sunflower oil (HOSFO), regular sunflower oil (RSFO), or linseed oil (LO)] was used to identify the type of diet consumed through linear discriminant analysis. Twenty variables (19 FA and 1 FA ratio) were selected as valid predictors out of 84 variables tested. The Mahalanobis squared distance was minimal between HOSFO and RSFO groups and maximal between control and LO groups. Cross-validation showed that only one observation from RSFO group was misclassified into the HOSFO group. We concluded that linear discriminant analysis is a useful method to classify milk fat samples from dairy goats according to the particular vegetable oil (of the 3 oils tested here) added to the basal diet.

Key words: discriminant analysis, fatty acid, goat milk, vegetable oil

\section{Short Communication}

Discriminant analysis is a multivariate statistical technique that can be used to build a predictive model of group discrimination based on observed predictor variables and to classify each observation into one of the groups. Linear discriminant analysis (LDA) has been used successfully to differentiate milk and cheese from different species based on their mineral content (Martín-Hernández et al., 1992) as well as to detect milk fat adulteration (Ulberth, 1994; Gutiérrez et al., 2009).

Received December 13, 2011.

Accepted February 21, 2012.

${ }^{1}$ Current address: Division of Nutritional Sciences, Cornell University, Ithaca, NY 14853.

${ }^{2}$ Corresponding author: mafl@if.csic.es
It is well established that supplementation of goat diets with fat sources rich in unsaturated FA substantially modifies the FA profile of milk fat (Chilliard et al., 2007). Accordingly, enabling researchers to obtain information about the type of dietary lipids consumed by the animals from milk fat FA data would be of great interest. The aim of this work was to investigate the use of LDA to identify the type of plant oil consumed by goats from data of their milk fat FA profile determined by GC.

Milk fat FA GC analysis (up to $82 \mathrm{FA}$ and $2 \mathrm{FA}$ ratios per sample, Table 1) involving 112 goat milk samples from 16 goats (Martínez Marín et al., 2011), 12 goats (Martínez Marín et al., 2012), and 12 goats (our unpublished results) were used to perform the discriminant analysis. All goats were fed the same basal diet. The analyses were grouped into 4 classes (28 analyses in each class): basal diet with no added fat (control), diet rich in cis-9-18:1 (high oleic sunflower oil, HOSFO), diet rich in cis-9, cis-12-18:2 (regular sunflower oil, RSFO), and diet rich in 18:3n-3 (linseed oil, LO). Of the 28 analysis corresponding to each of the classes with added oil (HOSFO, RSFO, and LO), 22 corresponded to milk from goats supplemented with $48 \mathrm{~g}$ of oil per day, and 6 corresponded to milk from goats supplemented with 32 (3 goats) or 66 (3 goats) g of oil per day.

Statistical analysis was performed using SAS software version 9.1.3 (SAS Institute, 2004). First, PROC STEPDISC was used to select the FA and ratios to be included as predictor variables in the model. Probability to enter and stay in the model was set at 0.10 and 0.15 , respectively. Following this, PROC DISCRIM was used to determine the coefficients for the optimal subset of FA and ratios included in the linear discriminant functions. In this procedure, the option CROSSVALIDATE was included to assess the robustness of the linear discriminant functions obtained.

Nineteen FA and 1 ratio were selected as predictor variables (Table 2). Canonical discriminant functions 1 and 2 explained up to $89.2 \%$ of total variance be- 
Table 1. Milk FA composition (mean $\pm \mathrm{SD}$ ) and univariate test of equality between group means of the diet classes used in the study

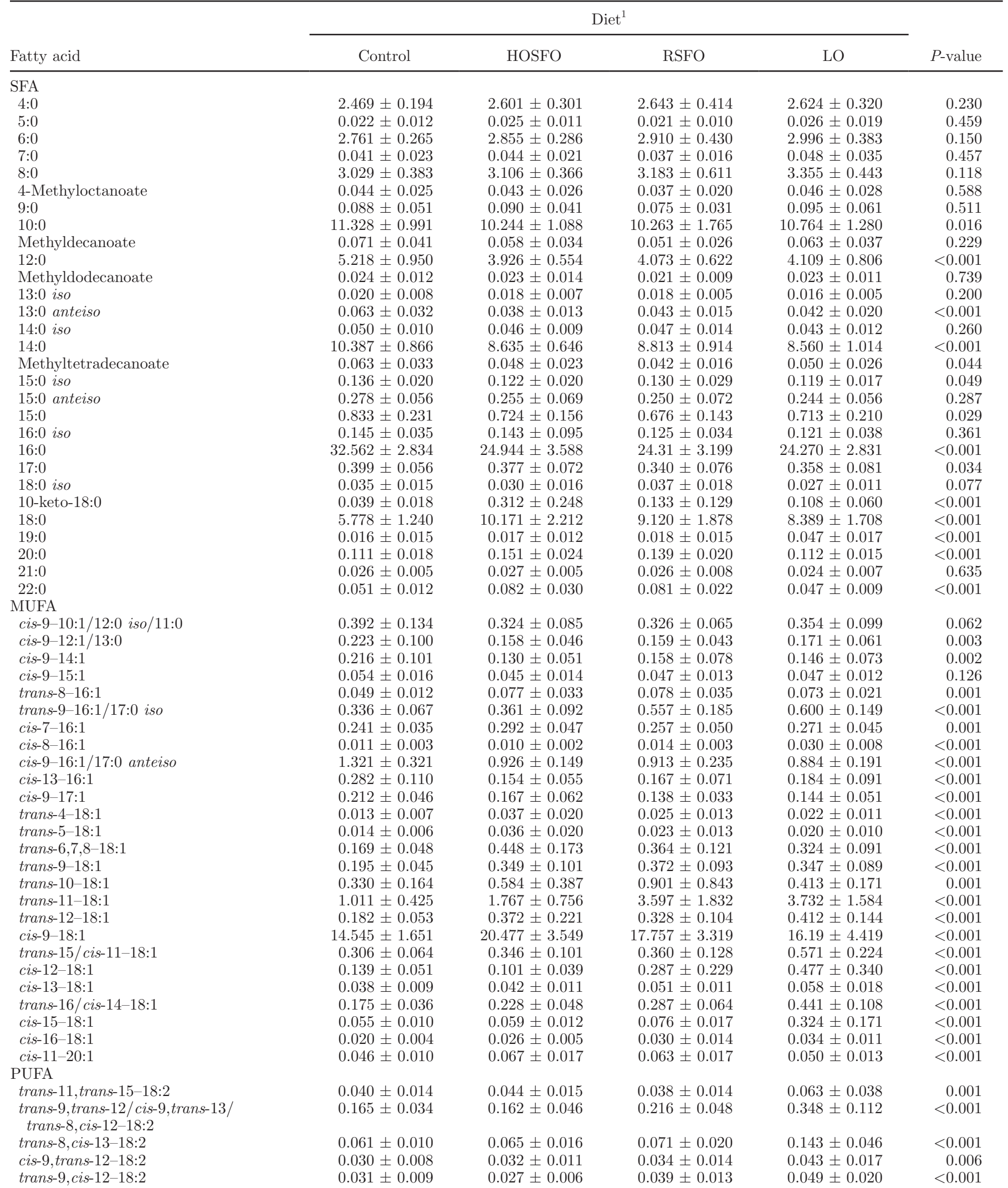


Table 1 (Continued). Milk FA composition (mean \pm SD) and univariate test of equality between group means of the diet classes used in the study

\begin{tabular}{|c|c|c|c|c|c|}
\hline Fatty acid & \multicolumn{4}{|c|}{$\operatorname{Diet}^{1}$} & $P$-value \\
\hline trans-11,cis-15-18:2 & $0.037 \pm 0.012$ & $0.056 \pm 0.023$ & $0.065 \pm 0.038$ & $0.936 \pm 0.561$ & $<0.001$ \\
\hline Other $18: 2$ & $0.063 \pm 0.025$ & $0.059 \pm 0.016$ & $0.050 \pm 0.015$ & $0.086 \pm 0.031$ & $<0.001$ \\
\hline cis-9,trans-11-18:2 & $0.616 \pm 0.246$ & $0.839 \pm 0.347$ & $1.679 \pm 0.837$ & $1.660 \pm 0.638$ & $<0.001$ \\
\hline trans-9, cis-11-18:2 & $0.013 \pm 0.007$ & $0.017 \pm 0.008$ & $0.021 \pm 0.013$ & $0.016 \pm 0.007$ & 0.016 \\
\hline trans- 12, trans- $14-18: 2$ & $0.007 \pm 0.003$ & $0.007 \pm 0.004$ & $0.009 \pm 0.006$ & $0.017 \pm 0.008$ & $<0.001$ \\
\hline trans-11,trans-13-18:2 & $0.006 \pm 0.003$ & $0.007 \pm 0.004$ & $0.007 \pm 0.004$ & $0.015 \pm 0.008$ & $<0.001$ \\
\hline trans-9,trans-11-18:2 & $0.013 \pm 0.006$ & $0.017 \pm 0.008$ & $0.022 \pm 0.014$ & $0.019 \pm 0.009$ & 0.016 \\
\hline $16: 2$ & $0.009 \pm 0.005$ & $0.011 \pm 0.005$ & $0.009 \pm 0.005$ & $0.051 \pm 0.034$ & $<0.001$ \\
\hline $18: 3 n-6$ & $0.026 \pm 0.008$ & $0.024 \pm 0.010$ & $0.024 \pm 0.007$ & $0.043 \pm 0.022$ & $<0.001$ \\
\hline $18: 3 n-3$ & $0.163 \pm 0.037$ & $0.128 \pm 0.028$ & $0.142 \pm 0.067$ & $0.614 \pm 0.291$ & $<0.001$ \\
\hline cis-9,trans-11,trans-15-18:3 & $0.007 \pm 0.003$ & $0.007 \pm 0.003$ & $0.010 \pm 0.009$ & $0.044 \pm 0.020$ & $<0.001$ \\
\hline $22: 4 n-6$ & $0.026 \pm 0.007$ & $0.076 \pm 0.049$ & $0.043 \pm 0.027$ & $0.030 \pm 0.011$ & $<0.001$ \\
\hline $22: 5 n-3$ & $0.040 \pm 0.009$ & $0.035 \pm 0.008$ & $0.038 \pm 0.015$ & $0.045 \pm 0.010$ & 0.024 \\
\hline $22: 6 n-3$ & $0.021 \pm 0.009$ & $0.019 \pm 0.008$ & $0.026 \pm 0.020$ & $0.018 \pm 0.009$ & 0.127 \\
\hline \multicolumn{6}{|l|}{ Ratio } \\
\hline trans-10-18:1/trans-11-18:1 & $0.349 \pm 0.161$ & $0.346 \pm 0.252$ & $0.251 \pm 0.188$ & $0.119 \pm 0.037$ & $<0.001$ \\
\hline LA:ALA ${ }^{2}$ & $10.972 \pm 2.280$ & $11.138 \pm 1.720$ & $16.577 \pm 5.434$ & $2.988 \pm 0.797$ & $<0.001$ \\
\hline
\end{tabular}

${ }^{1}$ Control = basal diet without added oil; HOSFO, RSFO, and LO = basal diet enriched with high oleic sunflower oil, regular sunflower oil, or linseed oil, respectively.

${ }^{2}$ Linoleic acid: $\alpha$-linolenic acid.

tween groups (Figure 1). The $4 \mathrm{FA}$ with the greatest discriminating ability were 19:0, cis-9-17:1, trans11,trans-15-18:2, and 18:0 iso, and the ratio linoleic acid to $\alpha$-linolenic acid (LA:ALA) in function 1; cis-9-18:1, trans-11-18:1, cis-9,cis-12-18:2, and trans-9,cis-12-18:2 in function 2; and cis-9-17:1, 18:0 iso, trans-5-18:1, and trans-9,cis-12-18:2 in function 3. Pooling within canonical structure (Table 2) showed that none of the predictor variables had an absolute correlation value $>0.41$ with any function. The higher correlation values between different $\mathrm{FA}$ and function 1 corresponded to 19:0, cis-8-16:1, trans-11-18:1, trans-9,cis-12-18:2, trans-11,cis-13-18:2, cis-9,trans11,trans-15-18:3, and LA:ALA. According to class means (Table 2), this function clearly discriminated the LO group. Some of the above-cited milk FA (e.g., trans-11-18:1, trans-11,cis-13-18:2, and cis-9,trans11,trans-15-18:3) are known to be related to the intake of diets rich in $\alpha$-linolenic acid by dairy ruminants (Collomb et al., 2004; Chilliard et al., 2007; Gómez-Cortés et al., 2009). The best correlation values between different FA and function 2 corresponded to 20:0, cis-7-16:1, cis-9-17:1, trans-5-18:1, trans-11-18:1, cis-9-18:1, and LA:ALA. According to class means, this function clearly discriminated the control group from groups
HOSFO and RSFO. Known FA that decrease with oil treatments, such as those of microbial origin, showed higher negative correlation values with function 2 (e.g., cis-9-17:1). In contrast, FA of direct or indirect dietary origin, such as trans-11-18:1, oleic acid, or LA:ALA showed a higher than average positive correlation value with this function. The higher correlation values between different FA and function 3 corresponded to cis-9,cis-12-18:2, 20:4n-6, trans-11-18:1, trans-5-18:1, cis-7-16:1, and cis-9-18:1, and to LA:ALA. According to class means, this function discriminated HOSFO from RSFO groups. The ratio LA:ALA and some FA with known direct or indirect origin in linoleic acid-rich diets (e.g., cis-9, cis-12-18:2, trans-11-18:1) were negatively correlated with function 3, whereas cis-9-18:1 was positively correlated, which suggests that HOSFO diets supplied more preformed cis-9-18:1 and stearic acid to the mammary gland.

Fisher's linear discriminant functions are shown in Table 3. The Mahalanobis squared distance was minimal between HOSFO and RSFO groups (26.99) and maximal between control and LO groups (146.26). The $F$-test of the distances was highly significant in all cases $(P<0.0001)$. Only one observation from the RSFO group was misclassified into the HOSFO group, both 
Table 2. Total sample standardized canonical coefficients and pooled within canonical structure (where 1, 2, and 3 are canonical functions)

\begin{tabular}{|c|c|c|c|c|c|c|}
\hline \multirow[b]{2}{*}{ FA } & \multicolumn{3}{|c|}{$\begin{array}{l}\text { Standardized canonical } \\
\text { coefficients }\end{array}$} & \multicolumn{3}{|c|}{ Canonical structure } \\
\hline & 1 & 2 & 3 & 1 & 2 & 3 \\
\hline 4:0 & -0.180 & 0.722 & 0.547 & 0.025 & 0.067 & -0.016 \\
\hline $14: 0$ iso & -0.011 & -0.049 & -0.727 & -0.042 & -0.029 & -0.031 \\
\hline 16:0 iso & -0.574 & -0.365 & 0.472 & -0.033 & -0.022 & 0.054 \\
\hline 18:0 iso & 0.965 & 0.320 & -1.133 & -0.042 & -0.001 & -0.111 \\
\hline 19:0 & 1.076 & -0.104 & 0.190 & 0.191 & -0.045 & 0.041 \\
\hline $20: 0$ & -0.043 & 0.608 & 0.460 & -0.076 & 0.288 & 0.113 \\
\hline cis-7-16:1 & -0.203 & -0.442 & 0.288 & 0.021 & 0.104 & 0.168 \\
\hline cis-8-16:1 & 0.762 & 0.056 & -0.096 & 0.390 & -0.077 & -0.069 \\
\hline cis-9-17:1 & -1.046 & -0.829 & 1.278 & -0.080 & -0.166 & 0.087 \\
\hline trans $-5-18: 1$ & -0.232 & -0.262 & 1.024 & -0.018 & 0.183 & 0.205 \\
\hline trans-11-18:1 & 0.634 & 1.249 & -0.498 & 0.151 & 0.164 & -0.236 \\
\hline cis-9-18:1 & 0.668 & 2.029 & -0.123 & -0.023 & 0.211 & 0.165 \\
\hline trans-11,trans-15-18:2 & -0.973 & -0.398 & 0.743 & 0.092 & -0.026 & 0.074 \\
\hline trans -9, cis- $12-18: 2$ & -0.257 & 0.945 & -0.918 & 0.133 & -0.013 & -0.139 \\
\hline cis-9, cis-12-18:2 & -0.464 & -1.011 & 0.191 & 0.000 & 0.035 & -0.291 \\
\hline trans-11,cis-13-18:2 & 0.475 & -0.470 & -0.275 & 0.147 & -0.030 & 0.026 \\
\hline cis-9,trans-11,trans-15-18:3 & 0.743 & -0.645 & 0.429 & 0.317 & -0.073 & 0.023 \\
\hline $20: 3 n-3$ & 0.026 & 0.595 & 0.503 & 0.034 & 0.042 & 0.032 \\
\hline $20: 4 n-6$ & 0.357 & -0.483 & -0.118 & -0.068 & 0.004 & -0.237 \\
\hline LA:ALA ${ }^{1}$ & -0.772 & 0.184 & -0.315 & -0.255 & 0.235 & -0.408 \\
\hline Eigenvalues & 20.34 & 7.84 & 3.43 & & & \\
\hline Canonical correlation & 0.976 & 0.942 & 0.880 & & & \\
\hline Variance explained (\%) & 64.35 & 24.80 & 10.85 & & & \\
\hline \multicolumn{7}{|l|}{ Class means ${ }^{2}$} \\
\hline Control & -3.654 & -4.074 & -0.253 & & & \\
\hline HOSFO & -2.390 & 2.312 & 2.505 & & & \\
\hline RSFO & -0.937 & 2.518 & -2.478 & & & \\
\hline $\mathrm{LO}$ & 8.022 & -0.984 & 0.377 & & & \\
\hline
\end{tabular}

${ }^{1}$ Linoleic acid: $\alpha$-linolenic acid.

${ }^{2}$ Control = basal diet without added oil; HOSFO, RSFO, and LO = basal diet enriched with high oleic sunflower oil, regular sunflower oil, or linseed oil, respectively.

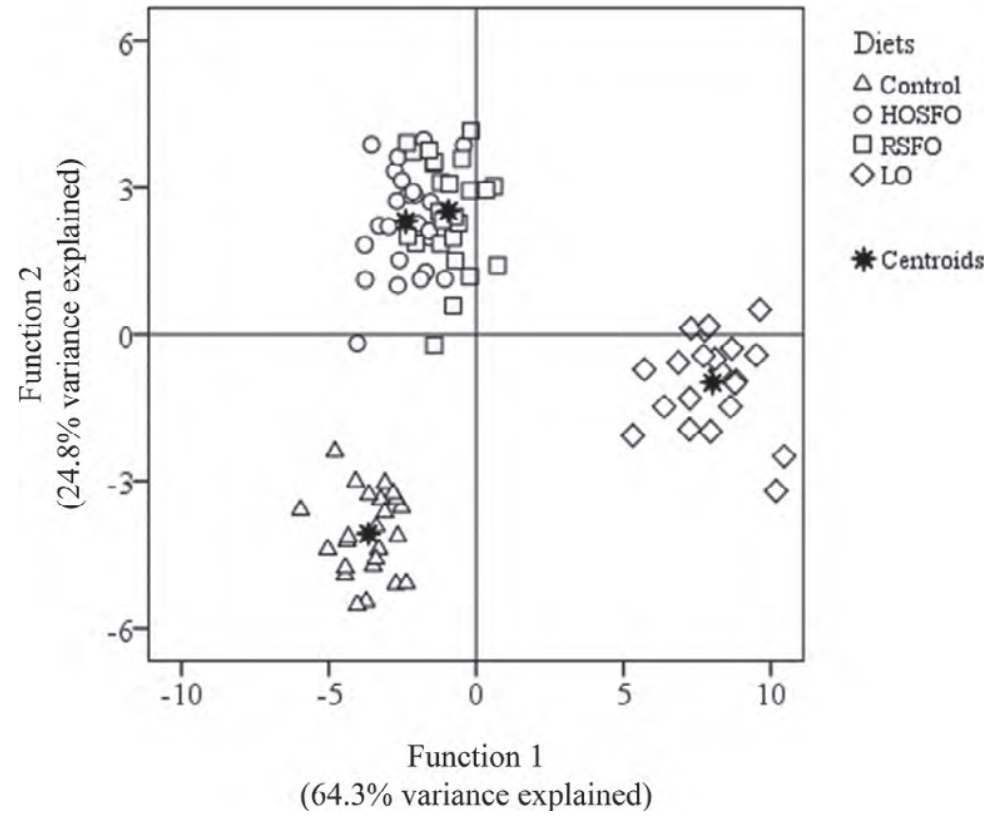

Figure 1. Canonical discriminant plot of the first 2 canonical variables. Control $=$ basal diet without added oil; HOSFO, RSFO, and LO = basal diet enriched with high oleic sunflower oil, regular sunflower oil, or linseed oil, respectively. 
Table 3. Coefficients of Fisher's linear discriminant functions for classifying milk fat samples

\begin{tabular}{|c|c|c|c|c|}
\hline \multirow[b]{2}{*}{ Selected variable } & \multicolumn{4}{|c|}{ Diet $^{1}$} \\
\hline & Control & HOSFO & RSFO & LO \\
\hline Constant term & -197.712 & -293.826 & -252.267 & -256.248 \\
\hline $4: 0$ & 87.435 & 105.961 & 97.035 & 88.928 \\
\hline 14:0 iso & -871.073 & $-1,075.907$ & -760.097 & -935.903 \\
\hline 16:0 iso & 4.470 & -26.318 & -83.582 & -127.807 \\
\hline 18:0 iso & -441.419 & -432.658 & 24.476 & 299.977 \\
\hline 19:0 & -176.505 & -94.471 & -54.180 & 656.837 \\
\hline $20: 0$ & 871.176 & $1,131.872$ & $1,017.772$ & 956.473 \\
\hline cis-7-16:1 & 78.035 & 27.031 & -13.538 & -1.278 \\
\hline cis-8-16:1 & -64.094 & 170.676 & 526.629 & $1,941.017$ \\
\hline cis-9-17:1 & 481.334 & 417.845 & 252.023 & 194.111 \\
\hline trans $-5-18: 1$ & 213.186 & 277.982 & -135.904 & -2.993 \\
\hline trans-11-18:1 & 4.535 & 10.310 & 13.166 & 13.078 \\
\hline cis-9-18:1 & 2.390 & 6.414 & 7.012 & 6.572 \\
\hline trans-11,trans-15-18:2 & 370.627 & 291.897 & 54.289 & -183.546 \\
\hline trans-9, cis-12-18:2 & -155.147 & 90.123 & 429.152 & -206.191 \\
\hline cis -9, cis- $12-18: 2$ & -15.865 & -27.826 & -31.195 & -31.328 \\
\hline trans-11,cis-13-18:2 & $-1,267.342$ & $-1,695.760$ & $-1,429.482$ & -736.150 \\
\hline cis-9,trans-11,trans-15-18:3 & -245.105 & -430.183 & -540.298 & 398.369 \\
\hline $20: 3 n-3$ & $2,509.141$ & $3,604.659$ & $3,112.623$ & $3,024.257$ \\
\hline $20: 4 n-6$ & -149.711 & -261.963 & -223.797 & -50.861 \\
\hline $\mathrm{LA}: \mathrm{ALA}^{2}$ & 1.461 & 1.250 & 1.402 & -1.260 \\
\hline
\end{tabular}

${ }^{1}$ Control $=$ basal diet without added oil; HOSFO, RSFO, and LO = basal diet enriched with high oleic sunflower oil, regular sunflower oil, or linseed oil, respectively.

${ }^{2}$ Linoleic acid: $\alpha$-linolenic acid.

in original and cross-validated classification matrices, resulting in $98.9 \%$ of original grouped cases being classified correctly.

Out of the 84 variables, LDA allowed us to identify 20 variables as useful predictors. The LDA was a useful method to classify milk fat samples according to the particular vegetable oil added to a basal diet, among the 3 studied, from several FA quantified in milk fat.

\section{ACKNOWLEDGMENTS}

The authors thank the Ministerio de Ciencia e Innovación (Projects Ref. AGL2008-04805 and Consolider Ingenio 2010 Ref. CSD/2007/00063 FUN-C-FOOD) and the Comunidad Autónoma de Madrid (Project Ref. S2009-AGR-1469 and S2009-AGR-1464) for their financial support.

\section{REFERENCES}

Chilliard, Y., F. Glasser, A. Ferlay, L. Bernard, J. Rouel, and M. Doreau. 2007. Diet, rumen biohydrogenation and nutritional quality of cow and goat milk fat. Eur. J. Lipid Sci. Technol. 109:828855 .
Collomb, M., R. Sieber, and U. Bütikofer. 2004. CLA isomers in milk fat from cows fed diets with high levels of unsaturated fatty acids. Lipids 39:355-364.

Gómez-Cortés, P., C. Tyburczy, J. T. Brenna, M. Juárez, and M. A. de la Fuente. 2009. Characterization of cis-9 trans-11 trans-15 C18:3 in milk fat by GC and covalent adduct chemical ionization tandem MS. J. Lipid Res. 50:2412-2420.

Gutiérrez, R., S. Vega, G. Díaz, J. Sánchez, M. Coronado, A. Ramírez, J. Pérez, M. González, and B. Schettino. 2009. Detection of nonmilk fat in milk fat by gas chromatography and linear discriminant analysis. J. Dairy Sci. 92:1846-1855.

Martínez Marín, A. L., P. Gómez-Cortés, A. G. Gómez Castro, M. Júarez, L. M. Pérez Alba, M. Pérez Hernández, and M. A. de la Fuente. 2011. Animal performance and milk fatty acid profile of dairy goats fed diets added differently unsaturated plant oils. J. Dairy Sci. 94:5359-5368.

Martínez Marín, A. L., P. Gómez-Cortés, A. G. Gómez Castro, M. Júarez, L. M. Pérez Alba, M. Pérez Hernández, and M. A. de la Fuente. 2012. Effects of feeding increasing dietary levels of high oleic or regular sunflower or linseed oil on fatty acid profile of goat milk. J. Dairy Sci. 95:1942-1955.

Martín-Hernández, C., L. Amigo, P. J. Martín-Alvarez, and M. Juárez. 1992. Differentiation of milks and cheeses according to species based on the mineral content. Z. Lebensm. Unters. Forsch. A 194:541-544.

SAS Institute. 2004. SAS/STAT 9.1 User's Guide. SAS Institute Inc., Cary, NC.

Ulberth, F. 1994. Detection of milk fat adulteration by linear discriminant analysis of fatty acid data. J. AOAC Int. 77:1326-1334. 